(US) examination of the $\mathrm{HJ}$ (Sono Diagnost 360 (Philips)) using linear (7,5 MHz) and convex $(5,0 \mathrm{MHz})$ transducers. A neck capsular pattern (NCP - the distance between the signals from inner surface of the femoral neck and the joint capsule) more than $7 \mathrm{~mm}$ was used as the US criterion, verifying the clinical diagnosis of coxitis.

Results: The US criterion of coxitis was found in 119 (53\%) out of 224 patients, and two groups of pts were analysed based on NCP values with $7 \mathrm{~mm}$ threshold.

\begin{tabular}{|c|c|c|c|c|c|}
\hline \multirow[t]{2}{*}{ Parameters } & \multicolumn{3}{|c|}{$P$} & \multirow[b]{2}{*}{$\begin{array}{l}\text { Group }^{1} \text { without US } \\
\text { signs of coxitis } \\
(n=105)\end{array}$} & \multirow[b]{2}{*}{$\begin{array}{c}\text { Group }^{2} \text { US } \\
\text { confirmed coxitis } \\
(n=119) \\
\end{array}$} \\
\hline & & & & & \\
\hline $\begin{array}{l}\text { Gender }(\mathrm{f} / \mathrm{m}), \mathrm{n} \\
\text { AS duration, } \\
\mathrm{mo}, \mathrm{Me}[25 \% \text {, } \\
75 \% ;]\end{array}$ & $\begin{array}{r}79 / 26 \\
43^{19 ; 80}\end{array}$ & $\begin{array}{c}77 / 40 \\
102^{24 ; 120}\end{array}$ & $\begin{array}{c}0,01 \\
0,0006\end{array}$ & & \\
\hline $\begin{array}{l}\text { BASDAI, } \\
\mathrm{Me}^{25 ; 75}\end{array}$ & $\begin{array}{c}4,1^{2,6} \\
5,5\end{array}$ & $5,2^{4,2 ; 6,7}$ & 0,0001 & & \\
\hline BASFI, Me ${ }^{25 ; 75}$ & $\begin{array}{c}2,4^{2,0} \\
3,8\end{array}$ & $3,4^{2,0 ; 5,4}$ & 0,0001 & & \\
\hline $\begin{array}{l}\text { HLA-B27, n } \\
\text { (\%) }\end{array}$ & $\begin{array}{c}96 \\
(91 \%)\end{array}$ & $\begin{array}{c}113 \\
(95 \%)\end{array}$ & 0,4 & & \\
\hline $\begin{array}{l}\text { ASDAS (?RP) } \\
? ?{ }^{25 ; 75}\end{array}$ & $2,8^{2,0}$ & $3,5^{2,6 ; 3,8}$ & 0002 & & \\
\hline $\begin{array}{l}\text { ESR, } \mathrm{mm} / \mathrm{h} \text {, } \\
\mathrm{Me}[25 \% \text {; } \\
75 \%]\end{array}$ & $10^{5 ; 25}$ & $25^{8 ; 35}$ & 0001 & & \\
\hline $\begin{array}{l}\mathrm{CRP}, \mathrm{mg} / \mathrm{mL} \text {, } \\
\mathrm{Me}[25 \% ; \\
75 \%]\end{array}$ & $\begin{array}{c}10,5^{3,8} ; \\
28,5\end{array}$ & $\begin{array}{c}23,0^{4,9} \\
43,5\end{array}$ & 0,06 & & \\
\hline $\begin{array}{l}\text { Peripheral } \\
\text { arthritis\% }\end{array}$ & $\begin{array}{c}38 \\
(36 \%)\end{array}$ & $28(30 \%)$ & 0,06 & & \\
\hline
\end{tabular}

Conclusions: US criterion of coxitis, i..e, increased NCP, was found in $53 \%$ of patients with clinical AS manifestations. Patients with US-confirmed coxitis demonstrate more active disease with greater functional impairment and longer history of AS, as compared to AS population without US signs of hip involvement.

Disclosure of Interest: None declared

DOI: 10.1136/annrheumdis-2018-eular.2044

\section{THU0253 THE CHRONIC SPINAL PAIN IN SPONDYLOARTHROPATHIES, OSTEOARTHRITIS, AND FIBROMYALGIA: THE ROLE OF CENTRAL SENSITISATION}

F.F. Ayhan ${ }^{1,2}$, Ö. F. Çelik ${ }^{1}$, M.A. Güler ${ }^{1} .{ }^{1}$ Department of Physical Medicine and Rehabilitation, Divisions of Rheumatology, Pain Medicine, Health Science University, Ankara Health Research and Training Hospital, Ankara; ${ }^{2}$ Department of Physical Therapy and Rehabilitation, Usak University, High School of Health Sciences, Usak, Turkey

Background: Central sensitisation (CS) is a new phenomenon associated with several medical diagnoses, including post-cancer pain, low back pain, osteoarthritis $(\mathrm{OA})$, whiplash, and fibromyalgia (FMS). ${ }^{1}$ Central sensitisation inventory (CSI) suggest the tool generates reliable and valid data that quantify the severity of several symptoms of $\mathrm{CS}$. $^{2}$

Objectives: To the best of our knowledge, there is no study to evaluate CS pain in patients with Spondylarthritis $(\mathrm{SpA})$. The aim of this study was to show the role of CS pain in patients with painful spine of SpA, OA, and FMS.

Methods: Totally 137 patients with chronic spinal pain (42 SpA, 45 OA and 50 FMS) were included. CSI consists of 2 parts $^{1,2}$ : CSI-A and CSI-B (restless leg, chronic fatigue, FMS, temporomandibular disorders, migraine/tension type headache, irritable bowel, multiple chemical sensitivity, whiplash, anxiety/panic attack, and depression).

Results: Only 4 patients $(9.52 \%)$ had active SpA (BASDAI $\geq 4$ ). Twelve patients (28.57\%) have used anti-TNF drugs. Age, BASDAI and VAS-pain scores were not related with SS-A or SS-P positivity. Spine in patients with SpA was less painful compared with them of OA and FMS $(p=0.001)$. The CS pain was detected in most with FMS, compared with OA, and SpA patients $(\mathrm{p}<0.001)$. Similarly, CSI-A score was the highest in patients with FMS group $(p<0.001)$ and similar in both $\mathrm{OA}$ and SpA groups ( $p=0.197)$. CS-related syndromes (CSI-B) were also detected similarly in both SpA and OA groups, but less than FMS group $(p<0.001)$. The numbers of CS syndromes were also similar in both SpA and OA $(p=0.551)$ and lower than FMS group $(p=0.003)$. Table 1 shows the clinical parameters in all groups.
Abstract THU0253 - Table 1. The comparisons of clinical characteristics

\begin{tabular}{lccccc}
\hline & $\mathbf{1 . S p A}$ & $\mathbf{2 . ~ O A}$ & 3.FMS & P1-3 & P2-3 \\
\hline Age & 41,0 & 61.2 & $45.22 \pm 8.6$ & 0233 & 0000 \\
& $\pm 10,03$ & \pm 9.67 & & & \\
Female\% & $\% 38.09$ & $\% 88.88$ & $\% 94$ & 0001 & 0370 \\
BASDAI & $2,42 \pm 1,18$ & & & & \\
VAS & $3,48 \pm 2,17$ & 6.78 & $8.00 \pm 1.8$ & 0000 & 0001 \\
& & \pm 1.70 & & & \\
CSI-A\% & $\% 45.23$ & $\% 62.22$ & $\% 94$ & 0000 & 0000 \\
CSI-Ascore & 36,26 & 43.6 & 58.92 & 0000 & 0000 \\
& $\pm 18,5$ & \pm 13.1 & \pm 14.78 & & \\
CSI-B\% & $\% 40.47$ & $\% 28.88$ & $\% 100$ & 0000 & 0000 \\
CSI-Bscore & $0,93 \pm 1,3$ & 0.51 & $1.98 \pm 1.2$ & 0000 & 0000 \\
& & \pm 1.05 & & & \\
Restless leg & $\% 9.52$ & $\% 4.44$ & $\% 8.00$ & 0796 & 0477 \\
Chr.fatigue & $\% 7.14$ & $\% 2.22$ & $\% 6$ & 0825 & 0360 \\
Fibromyalgia & $\% 7.14$ & $\% 2.22$ & $\% 100$ & 0000 & 0000 \\
TMD & $\% 11.90$ & $\% 17.77$ & $\% 0$ & 0012 & 0002 \\
Migraine/TTH & $\% 14.28$ & $\% 2.22$ & $\% 30$ & 0086 & 0231 \\
Irrit.bowel & $\% 9.52$ & $\% 2.22$ & $\% 5$ & 0285 & 0621 \\
Multi-chem s. & $\% 0$ & $\% 0$ & $\% 5$ & 0190 & 0175 \\
Whiplash & $\% 2.38$ & $\% 0$ & $\% 2$ & 0901 & 0340 \\
Anxiety/panic & $\% 14.28$ & $\% 2.22$ & $\% 18$ & 0779 & 0030 \\
Depression & $\% 16.22$ & $\% 15.55$ & $\% 28$ & 0222 & 0215 \\
\hline & & & & &
\end{tabular}

Conclusions: Central sensitisation should be considered in patients with chronic persistent pain, not only having FMS, but also half of the patients having SpA and $O A$. It is not a rare phenomenon and if it is exists, effective pain management strategies could be needed in addition to the specific pharmacologic treatment.

\section{REFERENCES:}

[1] O'Leary H, et al. Nervous System Sensitization as a Predictor of Outcome in the Treatment of Peripheral Musculoskeletal Conditions: A Systematic Review. Pain Pract 2017;17(2):249-266.

[2] Neblett R, et al. The Central Sensitization Inventory (CSI): The Journal of Pain 2013;14(5):438-45.

[3] Düzce E. SS Ölçeğinin Türkçe Geçerlilik\&Güvenilirliği. Trakya FTR AD Uzmanlık Tezi 2017.

Disclosure of Interest: None declared

DOI: 10.1136/annrheumdis-2018-eular.3916

\section{THU0254 RELATION BETWEEN SUBCLINICAL ULTRASONOGRAPHIC CHANGES OF THE ANTERIOR CHEST WALL JOINTS AND PULMONARY FUNCTION TESTS IN ANKYLOSING SPONDYLITISPATIENTS}

F.I. Abdelrahman ${ }^{1}$, M. Mortada ${ }^{1}$, W. Mansour ${ }^{2}$, A.B. Abdulsattar ${ }^{1}$. ${ }^{1}$ Rheumatology; ${ }^{2}$ Pulmonology, Zagazig University, Zagazig, Egypt

Background: Ultrasonography can detect subclinical changes in anterior chest wall (ACW) joints of patients with ankylosing spondylitis (AS). ${ }^{1}$

Pulmonary functions may be affected during the course of $A S^{2}{ }^{2}$

Up to the best of our knowledge, there are no previous studies of the relationship between ultrasound detected subclinical changes in ACW and the pulmonary functions in AS patients.

Objectives: To detect the relation between ultrasonographic changes of asymptomatic ACW joints and pulmonary function tests (PFTs) in patients with AS. Methods: The study included 88 sternoclavicular joints (SCJ) and 44 manibrusternal joints (MSJ) in 44 subjects (22 AS and 22 control). None of the participants had a history of respiratory complaints such as dyspnea, chronic cough, or chest pain. High resolution Computed Tomography (HRCT) was done on the chest to exclude interstitial lung problem that may affect chest expansion and PFTs.

Ultrasound (US) assessments were performed to detect synovitis, erosions, ankylosis, osteophytes, or Doppler signals. Chest expansion was measured. PFTs was done and included measurement of the forced expiratory volume in1 s (FEV1), forced vital capacity (FVC), and the ratio offorced expiratory volume in $1 \mathrm{~s}$ to the forced vital capacity(FEV1/FVC). In AS group, Ankylosing Spondylitis Disease Activity Score (ASDAS), Bath Ankylosing Spondylitis Disease Activity Index (BASDAI) and Bath Ankylosing Spondylitis Functional Index (BASFI) were recorded

Results: US detected subclinical changes of ACW joints in (77.3\%) of AS patient with significant difference between total US changes in AS(77.3\%) and control $(21.2 \%)(p<0.001)$. MSJ ankylosing was highly associated with limited chest 
expansion in AS group $(\mathrm{p}<0.001)$. PFTs were found to be restrictive in $14 \mathrm{AS}$ patient $(63.6 \%)$ with mean of FVC $(70.3 \pm 9) \%$, FEV1 $(55.2 \pm 15.9) \%$, FEV1/FVC $(80.1 \pm 2)$ and these restrictive PFTs were associated with SCJ synovitis $(p=0.03)$, SCJ PD activity $(p=0.03)$, SCJ erosions $(0.05)$ and highly associated with MSJ ankylosing $(p<0.001)$. All AS patients $(100 \%)$ with ankylosed MSJ by US had limited chest expansion and restrictive PFTs.

In AS group, ultrasonographic changes and restrictive PFTs were found to be higher with older age, male sex, smoking, longer disease duration and high BASDAI and BASFI.

Conclusions: Our study demonstrated that ultrasound detected subclinical changes in ACW joints is associated with restrictive pattern of PFTs in AS patients.

\section{REFERENCES:}

11] Abdelrahman F, Mortada M, Abdul Sattar A, et al. Annals of the Rheumatic Diseases 2017;76:733.

[2] Gunnhild Berdal, Silje Halvorsen, Désirée van der Heijde, Morten Mowe, et al. Arthritis Res Ther 2012;14(1):R19. doi:10.1186/ar3699

Disclosure of Interest: None declared

DOI: 10.1136/annrheumdis-2018-eular.5895

\section{THU0255 LOW BONE MINERAL DENSITY IS COMMON IN AXIAL SPONDYLOARTHROPATHY}

G. Fitzgerald, T. Anachebe, F. O' Shea. Department of Rheumatology, St James's Hospital, Dublin 8, Ireland

Background: Osteoporosis is a known consequence of inflammatory arthritis (IA). In the general population and IA such as rheumatoid arthritis, the impact of osteoporosis is well outlined. However, it is often ignored in axial spondyloarthropathy (axSpA), a form of IA centred on sacroiliac joints and the spine, as axSpA predominantly affects men, in whom osteoporosis is often not considered. As a result, osteoporosis prevalence figures are unclear, with wide variation in the literature. Accurate epidemiology regarding bone mineral density (BMD) in axSpA is crucial to begin understanding the impact of low BMD in this cohort.

Objectives: 1. Investigate the prevalence of low BMD in a well-characterised axSpA cohort

2. Explore relationships (demographic, disease-related, laboratory) between BMD and axSpA

Methods: A detailed assessment was performed on axSpA patients, including demographics, clinical characteristics and laboratory investigations. Disease severity was assessed with tools validated in axSpA: ASDAS-CRP and BASDAI (disease activity), BASMI (spinal mobility) and BASFI (function). BMD was assessed using DXA of the spine, hip and radius. Lateral vertebral assessment (LVA) was also performed. The WHO criteria were used to classify low BMD. SPSS was used for statistical analysis.

Results: One hundred and four patients with axSpA were consecutively recruited: $77.9 \%(n=81)$ male, $98.1 \%(n=102)$ Caucasian, mean (SD) age $51^{12}$ years, disease duration $26^{13}$ years. The mean (SD) ASDAS-CRP was 2.3 (1), BASDAI was 3.9 (2.2), BASMI was 4.3 (1.9) and BASFI was 3.8 (2.5), reflecting mild to moderate disease burden. A history of fracture was present in $42.3 \%$ $(n=44)$ of the cohort, with only 3 fragility fractures reported.

Of the cohort, $42.3 \%(n=44)$ had osteopenia and $16.3 \%(n=17)$ had osteoporosis. Low BMD was most prevalent at the spine, with $44 \%$ of the cohort affected, followed by the femoral neck $(30.1 \%, \mathrm{n}=22)$. Low BMD at the radius was uncommon $(<10 \%$ of the cohort). Only $6.4 \%$ of the cohort had a prior diagnosis of osteoporosis and only $39.4 \%$ had a previous DXA.

Three vertebral fractures were detected on LVA - all patients were unaware of these fractures prior to the study.

Female gender, higher BASFI, lower BMI and lower urate levels were significantly associated with bone loss at both the spine and the hip. ASDAS-CRP and BASDAI had no impact on low BMD. Additionally, longer disease duration was associated with spine BMD loss. Non-obese patients were more likely to have low BMD at any site than obese patients $(62.3 \% \vee 40 \%, O R 2.5, p=0.04)$. The use of biologics didn't influence BMD.

Conclusions: Low BMD is common in this axSpA cohort, with over $50 \%$ of patients affected. Most cases of low BMD were undiagnosed prior to this study and less than half of the cohort had ever had a DXA, suggesting a continued low awareness of the risk of osteoporosis in a male-dominated disease.

Disclosure of Interest: None declared

DOI: 10.1136/annrheumdis-2018-eular.6287

\section{THU0256 \\ HIGH DISEASE ACTIVITY, REDUCED PHYSICAL FUNCTION, LONG DISEASE DURATION, FATIGUE AND LIVING WITHOUT A PARTNER ARE FACTORS RELATED TO WORSE HEALTH RELATED QUALITY OF LIFE IN ANKYLOSING SPONDYLITIS}

H. Forsblad-D'elia ${ }^{1,2}$, L. Law ${ }^{1}$, J. Beckman Rehnman ${ }^{1}$, A. Deminger ${ }^{2}$

E. Klingberg' ${ }^{2}$, L. T.H. Jacobsson ${ }^{2} .{ }^{1}$ Department of Public Health and Clinical

Medicine, Rheumatology, Umeå University, Umeå; ${ }^{2}$ Institute of Medicine,

Sahlgrenska Academy at University of Gothenburg, Gothenburg, Sweden

Background: Ankylosing spondylitis (AS) begins early in life. The disease often leads to reduced physical function and also reduced health related quality of life (HRQoL). Knowledge is limited about factors related to HRQoL and how it develops over time.

Objectives: To assess HRQoL by SF-36 in a cohort of patients with AS com pared with controls and to explore associations between HRQoL and spinal radiographic damage, physical function, disease activity and demographic data.

Methods: A cohort of patients with AS from Western Sweden were assessed at baseline and after 5 years with; $x$-ray of the spine for mSASSS, clinical examination and questionnaires, including BASMI, BASFI, ASDAS, BASDAI and SF-36. In this abstract we report the baseline results. Each patient's SF-36 results were compared with 5 age- and sex matched persons $(n=1055)$ from the SF-36 Swedish normative population database. Associations between SF-36 mental component summary (MCS) and physical component summary (PCS) scores and disease related and demographic factors were investigated. Univariate logistic regression analyses were assessed with PCS and MCS below/above their respective median values (below median $=1$ and above median=0) as dependent variables and disease related and demographic variables as covariates. Variables with $p$-values $\leq 0.2$ in the univariate analyses were entered as covariates in multivariate models after checking for multicollinearity.

Results: 210 patients, age (median, IQR) 49.0 (40.0,61.2) years, symptom dura tion $24.0(13.0,34.0)$ years, men 58\%, HLAB27 87\% were included. AS patients scored significantly lower $(p<0.001)$ compared to controls in all SF-36 domains and component summaries. AS women scored significantly lower compared to AS men in three domains, Physical Function, Vitality and Mental Health. Both men and women scored significantly lower in PCS compared with MCS. The results of the multiple logistic regressions are shown in the table 1.

\begin{tabular}{lcccccc}
\hline & \multicolumn{2}{c}{ PCS below median $42.4(1)$} & \multicolumn{3}{c}{ MCS below median $48.0(1)$} \\
\hline Variables & OR & $95 \% \mathrm{Cl}$ & $P$-value & OR & $95 \% \mathrm{Cl}$ & $P$-value \\
\hline Civil state, single & 2.19 & $0.95-5.02$ & 0.065 & 3.12 & $1.40-6.97$ & 0.006 \\
VAS global fatigue, $>$ median & & & & 7.05 & $3.50-14.20$ & $<0.001$ \\
Duration of symptoms, decades & 1.59 & $1.16-2.17$ & 0.004 & & & \\
BASFI & 1.98 & $1.51-2.58$ & $<0.001$ & & & \\
ASDAS-CRP, $\geq 2.1$ & 3.37 & $1.58-7.20$ & 0.002 & 3.85 & $1.95-7.60$ & $<0.001$ \\
\hline
\end{tabular}

Conclusions: Patients with AS had significantly lower HRQoL compared with controls. Women with AS scored lower in some domains compared to men and PCS was more affected compared to MCS in both sexes. Both demographic and disease related factors were associated with $\mathrm{HRQ}$ oL, partly overlapping for PCS and MCS. By modifying factors, such as ASDAS and fatigue, HRQoL may potentially be improved. The development of SF-36 over 5 years will be investigated. Disclosure of Interest: H. Forsblad-D'elia Grant/research support from: Advisory Board Fees from Sandoz, Novartis and Abbvie and an unrestricted grant from Novartis, L. Law: None declared, J. Beckman Rehnman: None declared, A Deminger: None declared, E. Klingberg: None declared, L. T.H. Jacobsson: None declared

DOI: 10.1136/annrheumdis-2018-eular.3144

\section{THU0257 ASSOCIATIONS BETWEEN TRABECULAR BONE SCORE AND VERTEBRAL FRACTURES IN PATIENTS WITH AXIAL SPONDYLOARTHRITIS}

H.R. Kim, Y.S. Hong, K.Y. Kang. Catholic University of Korea, Seoul, Korea, Republic of Ireland

Background: The bone tissue directly exposed to inflammation in axSpA is the trabecular bone of the vertebrae, and consequently, vertebral osteoporosis and resorption of trabecular bone are increased in axial spondyloarthritis. The trabecu lar bone score (TBS) is a novel tool used to evaluate bone microarchitecture. AxSpA patients showed poor bone quality compared with matched controls.

Objectives: This study aims to compare TBS between axSpA patients with and without vertebral fractures and investigate associations between TBS and vertebral fractures. 